\title{
16S rRNA metagenomic analysis of the bacterial community associated with turf grass seeds from low moisture and high moisture climates
}

\author{
Qiang Chen ${ }^{1}$, William A. Meyer ${ }^{1}$, Qiuwei Zhang ${ }^{1}$, James F White ${ }^{\text {Corresp. } 1}$ \\ ${ }^{1}$ Department of Plant Biology, Rutgers, The State University of New Jersey, New Brunswick, NJ, United States \\ Corresponding Author: James F White \\ Email address: jwhite3728@gmail.com
}

Turfgrass investigators have observed that plantings of grass seeds produced in moist climates produce seedling stands that show greater stand evenness with reduced disease compared to those grown from seeds produced in dry climates. Grass seeds carry microbes on their surfaces that become endophytic in seedlings and promote seedling growth. We hypothesize that incomplete development of the microbiome associated with the surface of seeds produced in dry climates reduces the performance of seeds. Little is known about the influence of moisture on the structure of this microbial community. We conducted metagenomic analysis of the bacterial communities associated with seeds of three turf species (Festuca rubra, Lolium arundinacea, and Lolium perenne) from low moisture (LM) and high moisture (HM) climates. The bacterial communities were characterized by Illumina high-throughput sequencing of 16S rRNA V3-V4 regions. We performed seed germination tests and analyzed the correlations between the abundance of different bacterial groups and seed germination at different taxonomy ranks. Climate appeared to structure the bacterial communities associated with seeds. LM seeds vectored mainly Proteobacteria (89\%). HM seeds vectored a denser and more diverse bacterial community that included Proteobacteria (50 \%) and Bacteroides (39\%). At the genus level, Pedobacter (20\%), Sphingomonas (13\%), Massilia (12\%), Pantoea (12\%), and Pseudomonas (11\%) were the major genera in the bacterial communities regardless of climate conditions. Massilia, Pantoea and Pseudomonas dominated LM seeds, while Pedobacter and Sphingomonas dominated HM seeds. The species of turf seeds did not appear to influence bacterial community composition. The seeds of the three turf species showed a core microbiome consisting of 27 genera from phyla Actinobacteria, Bacteroidetes, Patescibacteria and Proteobacteria. Differences in seed-vectored microbes, in terms of diversity and density between high and low moisture climates, may result from effects of moisture level on the colonization of microbes and the development of microbe community on seed surface tissues (adherent paleas and lemmas). The greater diversity 
and density of seed vectored microbes in high moisture climates may benefit seedlings by helping them tolerate stress and fight disease organisms, but this dense microbial community may also compete with seedlings for nutrients, slowing or modulating seed germination and seedling growth. 


\section{16S rRNA Metagenomic Analysis of the Bacterial}

2 Community Associated with Turf Grass Seeds from

3 Low Moisture and High Moisture Climates

Corresponding Author:

Qiang Chen ${ }^{1}$, William A. Meyer ${ }^{1}$, Qiuwei Zhang ${ }^{1}$, James F. White Jr. ${ }^{1}$

${ }^{1}$ Department of Plant Biology, Rutgers, The State University of New Jersey, New Brunswick, NJ, USA

James F. White Jr. ${ }^{1}$

59 Dudley Road, New Brunswick, NJ, 08901, USA

Email address: jwhite3728@gmail.com

Turfgrass investigators have observed that plantings of grass seeds produced in moist

climates produce seedling stands that show greater stand evenness with reduced disease compared to those grown from seeds produced in dry climates. Grass seeds carry microbes on their surfaces that become endophytic in seedlings and promote seedling growth. We hypothesize that incomplete development of the microbiome associated with the surface of seeds produced in dry climates reduces the performance of seeds. Little is known about the influence of moisture on the structure of this microbial community. We conducted metagenomic analysis of the bacterial communities associated with seeds of three turf species (Festuca rubra, Lolium arundinacea, and Lolium perenne) from low moisture (LM) and high moisture (HM) climates. The bacterial communities were characterized by Illumina high-throughput sequencing of $16 \mathrm{~S}$ rRNA V3-V4 regions. We performed seed germination tests and analyzed the correlations 
30 ranks. Climate appeared to structure the bacterial communities associated with seeds. LM seeds

31 vectored mainly Proteobacteria (89\%). HM seeds vectored a denser and more diverse bacterial

32 community that included Proteobacteria (50\%) and Bacteroides (39\%). At the genus level,

33 Pedobacter (20\%), Sphingomonas (13\%), Massilia (12\%), Pantoea (12\%), and Pseudomonas

$34(11 \%)$ were the major genera in the bacterial communities regardless of climate conditions.

35 Massilia, Pantoea and Pseudomonas dominated LM seeds, while Pedobacter and Sphingomonas

36 dominated HM seeds. The species of turf seeds did not appear to influence bacterial community

37 composition. The seeds of the three turf species showed a core microbiome consisting of 27

38 genera from phyla Actinobacteria, Bacteroidetes, Patescibacteria and Proteobacteria. Differences

39 in seed-vectored microbes, in terms of diversity and density between high and low moisture

40 climates, may result from effects of moisture level on the colonization of microbes and the

41 development of microbe community on seed surface tissues (adherent paleas and lemmas). The

42 greater diversity and density of seed vectored microbes in high moisture climates may benefit

43 seedlings by helping them tolerate stress and fight disease organisms, but this dense microbial

44 community may also compete with seedlings for nutrients, slowing or modulating seed

45 germination and seedling growth.

47 Introduction

Plants bear numerous microbes that influence their nutrition, development, stress

responses and phenotypes (Henning et al., 2016; White et al., 2014; White et al., 2018). Plant-

50 associated microbes generally come from the surrounding environment; however, Johnston-

51 Monje and Rhizada (2011) showed that corn seeds vectored a diverse array of microbes. Further,

52 Johnston-Monje et al. (2016) found that the rhizospheres of corn seedlings were composed of 
53 microbes that originated both from seeds and bacteria recruited from soils. These seed-vectored

54 bacteria can influence germination and share a mutualistic association with the host seedlings

55 (Cruz et al., 2014; Shaid \& Thomas, 2019; Somova et al., 2001; Zhu et al., 2017). Without seed-

56 vectored bacteria, seedlings may lose gravitropic response of roots, fail to develop root hairs, and

57 are more susceptible to soil-borne pathogens (Verma et al. 2017, 2018).

58 Some turf grasses possess fungal endophytes of ascomycete genus Epichloë that provide

59 resistance to pathogens and insects, and increase abiotic stress tolerance in the host (Bultman \&

60 Bell, 2003; Clay, 1990; Meyer et al., 2012; White, 1987). Turf breeders have long been

61 employing these environmentally safe endophytes to enhance turfgrass performance and stress

62 tolerance (Meyer et al., 2012). Another important microbe resource, the seed-transmitted

63 bacterial communities of turf grasses, are yet to be fully explored. Many of these bacteria are

64 vectored on the surfaces of seeds and embedded within dried plant tissues (paleas and lemmas)

65 that adhere tightly to seed surfaces (White et al., 2019). During seed germination some of these

66 seed-surface microbes are activated and they externally and internally colonize seedling roots at

67 the root tip meristems, becoming intercellular and intracellular endophytes in the emergent

68 seedling roots (Verma et al., 2017, 2018; White et al., 2018). In this study, we employed

69 Illumina HTS and 16S metagenomic analysis to investigate the bacterial community associated

70 with cool-season turfgrass seeds produced in low moisture (LM) and high moisture (HM)

71 climates. We also evaluated the potential influence of the bacterial community on seed

72 germination rates and seedling growth rates. The results showed that HM seeds vectored a denser

73 and more diverse bacterial community than LM seeds. Also, bacterial groups at different

74 taxonomic ranks correlated with the seed germination rate and time. 


\section{Materials \& Methods}

\section{Total DNA extraction from seeds of cool-season turfgrasses}

78

79

80

81

82

83

84

85

86

87

91

92

93

94

95

96

97

Seeds of twenty-seven cool-season turf cultivars were obtained from DLF Pickseed USA (Table S1). All varieties were produced from 2011 to 2015 at either Store Hedinge, Denmark or Les Alleuds, France. Based on the precipitation data collected from The National Oceanic and Atmospheric Administration (NOAA), the seeds were classified into LM seeds (annual precipitation $<750 \mathrm{~mm}$ ) and HM seeds (annual precipitation $>750 \mathrm{~mm}$ ). With this classification, five samples were classified as LM seeds while twenty-two samples as HM seeds. 100mg of seeds of each turf cultivar were weighed out and washed with water for 3 times, 30 seconds each time to remove the dirt. The cleaned seeds were then ground into powder with a sterilized mortar and pestle for total DNA extraction. The DNA extraction was conducted with DNeasy® PowerSoil ${ }^{\circledR}$ Kit (QIAGEN, Hilden, Germany) following the manufacturer's instructions. This PowerSoil ${ }^{\circledR}$ Kit was chosen due to its versatility with diverse sample types. The concentration of extracted DNA was measured with The NanoDrop® ND-1000 Spectrophotometer and normalized to $5 \mathrm{ng} / \mu \mathrm{l}$ for the library preparation.

\section{Library preparation and sequencing}

The preparation of DNA libraries for each sample followed the Illumina guidelines. By using $12.5 \mathrm{ng}$ of the normalized DNA from turf seeds as the template, V3-V4 hypervariable regions of bacterial 16S rRNA gene were amplified with the primer pair, S-D-Bact-0341-b-S-17 (5'-CCTACGGGNGGCWGCAG-3') and S-D-Bact-0785-a-A-21 (5'-

7 GACTACHVGGGTATCTAATCC-3') fused with Illumina overhang forward adapters (5'9 TCGTCGGCAGCGTCAGATGTGTATAAGAGACAG-3') and reverse adapter (5’- 
99 GTCTCGTGGGCTCGGAGATGTGTATAAGAGACAG-3'), respectively (Klindworth et al.,

100 2013). PCR clean-ups were conducted to purify the 16S V3-V4 amplicons away from free

101 primers and primer dimers. Nextera XT index primers were then used for the index PCR and

102 PCR clean-ups were performed again to generate the final library. The generated 16S V3-V4

103 region library was paired-end sequenced ( 2 x 300bp) on an Illumina MiSeq platform in the

104 Genome Cooperative Sequencing Facility, School of Environmental and Biological Sciences at 105 Rutgers.

106

\section{Bacterial community structure analysis}

The collected sequencing data in FASTQ format was processed and analyzed with the

QIIME2 software suite (Caporaso et al., 2010). The raw Illumina reads were imported into

QIIME2 with “Casava 1.8 paired-end demultiplexed fastq” method, and then denoised and

filtered with dada2 pipeline to remove noisy and chimeric sequences, construct denoised pairedend sequences, and dereplicate them (Callahan et al., 2016). de novo clustering was then carried out with VSEARCH plugin at 99\% identity to generate Operational Taxonomic Units (OTUs)

114 (Rognes et al. 2016). The taxonomy assignment of OTUs was performed by using featureclassifier against the SILVA 1.28 database (Released September 29, 2016). After removing

116 mitochondria and chloroplast sequences, the filtered data were aligned with mafft program and 117 fasttree method to generate rooted and unrooted phylogenetic trees (Price et al., 2010). All core

118 metrics used in alpha and beta diversity analysis were computed based on the rooted

119 phylogenetic tree. Alpha diversity (intra group diversity) was calculated with the observed OTUs 120 and Faith's Phylogenetic Diversity (Faith, 1992) at the sample depth of 1000 reads to normalize

121 the variance and this excluded 4 samples (3 HM samples and 1 LM sample), leaving 4 LM 
122 samples and $19 \mathrm{HM}$ samples. The Kruskal-Wallis (pairwise) test was utilized to assess the

123 statistical significance of alpha diversity. Beta diversity was performed with both qualitative

124 (Jaccard and unweighted UniFrac) and quantitative (Bray-Curtis and weighted UniFrac) distance

125 metrics at sample depth of 1000 reads. In this process, QIIME2 diversity plugin was employed.

126 Statistical significance among different groups was evaluated by permutation-based ANOVA

127 (PerMANOVA) test (Anderson, 2005) with 999 permutations (beta-group-significance command

128 in diversity plugin). Principal coordinates analysis plots (PCoA) were generated by Emperor tool

129 of QIIME2 to explore the bacterial community structure. The bar plots showing taxonomy levels

130 were generated by QIIME2 taxa plugin. The metagenomic analysis workflow is shown in Fig. 1.

131 The Venn diagram was generated with a WWW-based tool to calculate the intersection(s)

132 of the list of elements that in this study was represented by the list of genera of bacteria found in

133 each climate condition and species. The graphical output is in the form of a Venn/Euler diagram.

Seed germination test

Seeds of 19 cool-season cultivars were placed in Petri dishes containing $25 \mathrm{ml} 1.5 \%$ agar.

All Petri dishes were kept in a growth chamber at $28^{\circ} \mathrm{C}$. Seed germination was observed every

24 hours until no more seed germinated. Seed germination rates and time for each sample were calculated and correlation analysis was performed and visualized with python-based libraries SciPy (V0.19.1), pandas (V0.22.0), seaborn (V0.9.0) and matplotlib (V2.2.3).

\section{Results}

\section{Sequence analysis}


In total, 7,405,226 sequences (about 274,368 sequences per sample) were generated by

145 Illumina MiSeq sequencing and imported into QIIME2 pipeline suite for analysis. After being

146 denoised and dereplicated with dada2 pipeline, the remaining high-quality sequences were

147 clustered into 310 OTUs that had an average length of $427 \mathrm{bp}$, ranging from $267 \mathrm{bp}$ to $440 \mathrm{bp}$.

148 After the removal of mitochondrial and chloroplast genomes, a total of 247 OTUs were used to 149 represent the bacterial profile of turf seeds samples (Table S2).

150

\section{Diversity of bacterial endophytes associated with turf seeds from LM and HM climates}

152

The bacterial community associated with turf seed samples was composed of 5 phyla, 8

classes, 21 orders, 37 families and 69 genera. The bacterial community vectored by seeds

produced in HM climates covered all discovered taxonomies, with 6644 sequences/sample.

However, seeds from LM climate only hosted part of them, 4 phyla, 8 classes, 9 orders, 10

families and 15 genera, with 2821 sequences/sample.

157

Regardless of the climate and turf species, bacterial communities at phylum level were

of the bacterial community on HM and LM climates seeds, respectively. Bacteroidetes was

abundant in HM climate seeds (39\%) but not LM climate seeds (2\%). Actinobacteria (6\%) and

Firmicutes (3\%) also comprised a portion of the bacterial community and exhibited no significant difference between the two climate types.

Both HM and LM seeds shared some of the most abundant bacterial classes, i.e.

Actinobacteria, Bacteroidia, Bacilli, Alphaproteobacteria and Gammaproteobacteria (Fig. 2).

Compared to LM seeds, seeds from HM environment was richer in terms of Faith's Phylogenetic diversity (Fig. 3 \& Table S3). At class level, Actinobacteria, Bacteroidia and Bacilli had the same 
167 portion as phyla Actinobacteria, Bacteroidetes and Firmicutes, respectively (Table 1).

168 Alphaproteobacteria and Gammaproteobacteria were the two classes within phylum

169 Proteobacteria. Alphaproteobacteria took $6 \%$ and $18 \%$ of the bacterial community of LM and

170 HM climate seeds, respectively. Gammaproteobacteria was $83 \%$ and $32 \%$ for LM and HM

171 climate, respectively.

172 At genus level, LM seeds harbored a significantly higher percentage of Massilia $(\mathrm{p}=$

173 0.013), Pantoea $(\mathrm{p}=0.060)$, and Pseudomonas $(\mathrm{p}=0.045)$ compared to HM seeds $($ Table 1$)$. In

174 contrast, HM seeds harbored more of Flavobacterium $(\mathrm{p}<0.001)$, Chryseobacterium $(\mathrm{p}<$

175 0.001), Pedobacter $(\mathrm{p}<0.001)$, Sphingomonas $(\mathrm{p}=0.035)$ and Erwinia $(\mathrm{p}=0.122)($ Table 1).

176 PCoA separated bacterial communities associated with turf seeds by climate (Fig. 4).

177 Also, the PERMANOVA test showed a significant difference between the two groups $(\mathrm{p}=$

178 0.002, Table S4). However, no significant correlation was detected between different species of

179 turf seeds and their bacterial profile (F. rubra vs L. arundinacea, $\mathrm{p}=0.101 ; F$. rubra vs $L$.

180 perenne, $\mathrm{p}=0.109 ;$ L. arundinacea vs L. perenne, $\mathrm{p}=0.204$, Table S4).

LM seeds didn't bear any unique bacteria genus that HM seed didn't (Fig. 5A \& Table

182 S5). However, HM seeds harbored 55 genera that LM seeds didn't. Seeds of three turf species

183 shared 4 phyla and 27 genera, including five genera that were uncultured or unknown species

184 from either Bacterioidetes or Patescibacteria (Fig.5B \& Table 2).

185

Correlation of seed germination and bacterial endophyte composition associated with turf

187 seeds

Bacterial groups at different taxonomic ranks correlated with the seed germination rate and time (Fig. $6 \&$ Fig. 7). Among the 5 phyla that we discovered through diversity analysis, 
190 Proteobacteria correlated positively with the seed germination rate $(p=0.028)$ and negatively with 191 the seed germination time $(\mathrm{p}=0.016)$. Phylum Actinobacteria also showed a negative correlation 192 with the seed germination time $(\mathrm{p}=0.040)$ but not a significant correlation with germination rate $193(\mathrm{p}=0.120)$. Another phylum, Firmicutes, showed correlation with germination $(\mathrm{p}=0.109)$ rate and 194 germination time ( $\mathrm{p}=0.069)$, but this was not statistically significant. However, the abundance of 195 Bacteroidetes was negatively associated with the seed germination rate $(p=0.008)$, and positively 196 associated with the seed germination time $(\mathrm{p}=0.002)$.

At class level, Bacilli and Gammaproteobacteria were groups showing exactly the same

198 199 200 201 202 203 204 205 206 207 208 209 210 211 correlation as phyla Firmicutes and Proteobacteria, respectively (Fig. 6 \& Fig. 7). Also, the abundance of Bacteroidia and Gammaproteobacteria showed a similar correlation to phylum Bacteroidetes and Proteobacteria.

At family level, seed germination rate was positively related to the abundance of bacteria from families Microbacteriaceae $(p=0.090)$, Paneibacillaceae $(p=0.109)$ and Pseudomonadaceae $(\mathrm{p}=0.138)$, and negatively associated with the abundance of bacteria from Rhizobiaceae $(p=0.014)$, Sphingobacteriaceae $(p=0.005)$, and Weeksellaceae $(p=0.033)$. As expected, seed germination time also correlated negatively with the abundance of these bacterial families. Seed germination time was positively associated with Rhizobiaceae $(p=0.004)$, Sphingobacteriaceae $(p=0.002)$, and Weeksellaceae $(p=0.008)$, but negatively with Microbacteriaceae $(p=0.032)$ and Paneibacillaceae (0.069) and Pseudomonadaceae $(p=0.049)$.

At genus level, the abundance of Rhizobium, Chryseobacterium and Pedobacter was negatively associated with germination rate ( $\mathrm{p}$-value $0.041,0.033$, and 0.004 , respectively) but

211 positively with germination time (p-value $0.015,0.008$, and 0.001 , respectively). But the abundance of Pseudomonas was positively related with germination rate $(\mathrm{p}=0.138)$ but 
213 negatively associated with the germination time $(\mathrm{p}=0.049)$, although the correlation was not 214 significant.

215

216 Discussion

217

218 A complex bacterial community associated with turf seeds

219 Compared to LM seeds, HM seeds harbored a more diverse bacterial community with 220 many more bacterial cells (i.e., a higher bacterial load), as there were more sequences associated

221 222 223 224 225 226 227 228 229 230 231 232 233 234 235 with HM seeds. The More Individuals Hypothesis, which predicts that communities with more individuals will have more species (Storch, Bohdalková \& Okie, 2018), can explain the higher diversity associated with HM seeds. This result is similar to previous studies on soils indicating that moisture controls the structure and function of the soil microbial community (Brockett et al., 2012; Griffiths et al., 2003; Steven et al., 2013). Water availability in soil controls bacterial composition (Zeglin et al., 2011). Similarly, relatively high moisture will favor growth and replication of bacteria on seeds, while low moisture conditions will suppress development of the bacterial community associated with seeds.

Both LM and HM seeds vectored a large number of bacteria and shared some groups. For example, the abundance of Curtobacterium spp. was similar in both LM and HM seeds (LM 2\%, HM 2\%). Curtobacterium is a Gram-positive endophytic bacterial genus in rice seeds (Oryza sativa), field-grown tall fescue (Lolium arundinacea) and Noccaea goesingensis (de los Santos et al., 2015; Mano et al., 2006; Ruiz et al., 2011). Some Curtobacterium strains provide host growth promotion and pathogen antagonistic effects (de los Santos et al., 2015; Ruiz et al., 2011). Paenibacillus was the only genus from phylum Firmicutes in both LM and HM seeds 
236 (LM 3\%, HM 4\%). Paenibacillus have been isolated from many plants and shown to produce 237 IAA, solubilize phosphate, and inhibit the growth of phytopathogens (Aswathy et al., 2013; Diaz 238 Herrera et al., 2016; Ruiz et al., 2011; Rybakova et al., 2015).

239 Two of the genera, Mucilaginibacter and Rhizobium, were found in HM seeds but not 240 LM seeds. Mucilaginibacter spp. can promote plant growth and produce extracellular 241 polysaccharides (An et al., 2009; Lee et al., 2013; Madhaiyan et al., 2010; Mannisto et al., 2010). 242 Rhizobium together with Allorhizobium, Neorhizobium, and Pararhizobium, composed 2\% of the 243 bacterial community on HM seeds. These genera comprise well-studied bacteria that promote 244 growth of plants and nodulate legumes to fix nitrogen (Gutierrez-Zamora \& Martınez-Romero, 245 2001; Kiers et al., 2003; Yanni et al., 1997). At the phylum level, LM seeds hosted more Gammaproteobacteria than HM seeds. 247 Several genera within Gammaproteobacteria contributed to these results, i.e. Duganella, 248 Massilia, Pantoea, and Pseudomonas. However, these bacteria were still found on a large 249 portion of the HM seeds. Duganella spp. can suppress the growth of plant pathogens (Cretoiu et 250 al., 2013; Haack et al., 2016). Massilia is a root-colonizing bacterial genus with the ability to 251 degrade chitin (Adrangi et al., 2010; Faramarzi et al., 2009; Ofek et al., 2012). Pantoea spp. 252 promote plant growth and tolerance of environmental stresses (Chen et al., 2017; Feng et al., 253 2006; Ferreira et al., 2008; Gond et al., 2015b). Pseudomonas contains many endophytic 254 bacterial strains that benefit hosts by producing IAA, producing biocontrol lipopeptides, and 255 solubilizing phosphate (Oteino et al., 2015; Prieto \& Mercado-Blanco, 2008; Suzuki et al., 256 2003).

Some bacterial genera were more abundant in HM seeds than LM seeds, including 258 Flavobacterium, Chryseobacterium, Pedobacter, Sphingomonas, and Erwinia. Most of the 
259 bacteria comprised a very small portion of the bacterial community of LM seeds, but

260 Sphingomonas made up 6\%. Flavobacterium sp. has been found to promote plant growth and

261 provide biocontrol activity to the hosts (Kolton et al., 2016; Soltani et al., 2010).

262 Chryseobacterium spp. were also shown to be plant growth promoting bacteria (Dardanelli et al.,

263 2009; Gutiérrez Mañero et al., 2003). Although Pedobacter has not been found to promote

264 growth of plants, it can induce the production of antimicrobial compounds by Pseudomonas

265 fluorescens Pf0-1 (Garbeva et al., 2011). Sphingomonas is an alphaproteobacterial genus

266 containing strains that produce IAA and provide nutrients to hosts (Okunishi et al., 2005; Ruiz et

267 al., 2011). Erwinia spp. have also been identified as endophytes in some plant species (Verma,

268 2019). However, genus Erwinia is well-known to contain many plant pathogenic species.

269 In total, the above genera together comprised $89 \%$ and $95 \%$ in HM and LM seeds,

270 respectively. Some of the bacterial genera include plant pathogens, e.g. Ewrinia and

271 Pseudomonas. However, most of the bacteria are known to contain mainly plant growth

272 promoting rhizobacteria (PGPR), e.g. Paenibacillus, Pseudomonas, Rhizobium, Pantoea. The

273 seed microbes are important because they stimulate seedling development, increase stress

274 tolerance in seedlings and protect seedlings from disease (Verma et al., 2017, 2018; White et al.,

275 2018, 2019). Thus, a more diverse bacterial community on HM seeds may provide hosts with

276 more microbial resources to utilize for plant development and stress tolerance.

277 In the study, the samples of LM and HM seeds had unequal sizes (LM: 4; HM: 19),

278 which could create a bias in our final result. However, HM seeds vectored a more diverse

279 bacterial community with significantly more bacteria cells (Fig. $3 \&$ Table S3). Also, the

280 different abundances between bacterial groups were statistically significant. 


\section{The bacterial community affected seed germination and growth}

283

284

285

286

287

288

289

290

291

292

293

294

295

296

297

298

299

300

301

302

303

304

Seeds from HM climates tended to show slower germination and reduced seedling

growth rates. These seeds vectored a denser and more diverse community of bacteria, which may benefit seedlings but not without a cost. We hypothesize that the higher microbial load competes with seedlings, which slows germination and development of the host. This nutritional cost may result in slower seed germination and seedling development rates. Seed growers have observed that seed from high moisture climates seems to establish better with reduced damping-off disease compared to seed from low moisture climates (W. Meyer, Unpublished data). While, seeds with richer and denser microbiomes grow slower initially, they may be better protected from soil borne pathogens than seeds with less developed microbiomes.

Seeds that have formed in low moisture situations, or where the natural microbiome has otherwise been damaged, could be remediated through application of microbes in seed coatings (Pedrini et al., 2017). Coating formulations with the correct microbes at the optimal concentrations could result in better fitness of seeds and seedlings.

\section{Conclusions}

We surveyed the bacterial community associated with seeds of several species of coolseason turfgrasses and identified the dominant bacterial groups of the communities at different taxonomic levels. Regardless of the moisture level during seed production and species of seeds, the core bacterial community included many PGPB strains. Seeds produced in high moisture conditions maintained a denser and more diverse bacterial community than seeds produced in low moisture conditions. This seed microbiome may help seedlings tolerate stress but may also compete with seedlings for nutrients and slow early seedling growth. 


\section{Acknowledgements}

307 The authors appreciate the support of Steve Reid (DLF Pickseed USA) for providing the seed 308 resources. The authors also thank the Department of Plant Biology, Rutgers University, NJ for 309 research facilities.

310

\section{References}

312 Adrangi S, Faramarzi MA, Shahverdi AR, Sepehrizadeh Z. 2010. Purification and

313 characterization of two extracellular endochitinases from Massilia timonae. Carbohydrate

314 Research 345:402-407. DOI 10.1016/j.carres.2009.11.015

315

316 An DS, Yin CR, Lee ST, Cho CH. 2009. Mucilaginibacter daejeonensis sp. nov., isolated from 317 dried rice straw. International Journal of Systematic and Evolutionary Microbiology 59:1122-

318 1125. DOI 10.1099/ijs.0.003384-0

319

Anderson MJ. 2005. PERMANOVA: a FORTRAN computer program for permutational 321 multivariate analysis of variance. Department of Statistics, University of Auckland, New Zealand 32224.

323

324 Aswathy AJ, Jasim B, Jyothis M, Radhakrishnan EK. 2013. Identification of two strains of 325 Paenibacillus sp. as indole 3 acetic acid-producing rhizome-associated endophytic bacteria from 326 Curcuma longa. 3 Biotech 3:219-224. DOI 10.1007/s13205-012-0086-0 
328 Brady SM, Sarkar SF, Bonetta D, McCourt P. 2003. The ABSCISIC ACID INSENSITIVE 3

329 (ABI3) gene is modulated by farnesylation and is involved in auxin signaling and lateral root 330 development in Arabidopsis. The Plant Journal 34:67-75. DOI 10.1046/j.1365-

$331 \quad \underline{313 X .2003 .01707 . x}$

332

333 Brockett BFT, Prescott CE, Grayston SJ. 2012. Soil moisture is the major factor influencing 334 microbial community structure and enzyme activities across seven biogeoclimatic zones in 335 western Canada. Soil Biology and Biochemistry 44:9-20. DOI 10.1016/j.soilbio.2011.09.003

Bultman TL, Bell GD. 2003. Interaction between fungal endophytes and environmental stressors influences plant resistance to insects. Oikos 103:182-90. DOI 10.1034/j.1600-0706.2003.11574.X

339

Callahan BJ, McMurdie PJ, Rosen MJ, Han AW, Johnson AJ, Holmes SP. 2016. DADA2: High341 resolution sample inference from Illumina amplicon data. Nature Methods 13, 581-583. DOI $\underline{10.1038 / \text { nmeth.3869 }}$

343

344 Caporaso JG, Kuczynski J, Stombaugh J, Bittinger K, Bushman FD, Costello EK, Fierer N, Peña 345 AG, Goodrich JK, Gordon JI. 2010. QIIME allows analysis of high-throughput community 346 sequencing data. Nature Methods 7:335-336. DOI 10.1038/nmeth.f.303

348 Chen C, Xin K, Liu H, Cheng J, Shen X, Wang Y, Zhang L. 2017. Pantoea alhagi, a novel 349 endophytic bacterium with ability to improve growth and drought tolerance in wheat. Scientific 350 Reports 7:41564. DOI 10.1038/srep41564 
351

352 Clay K. 1990. Fungal endophytes of grasses. Annual Review of Ecology and Systematics 21:275353297.

354

355 Cretoiu MS, Korthals GW, Visser JH, van Elsas JD. 2013. Chitin amendment increases soil 356 suppressiveness toward plant pathogens and modulates the actinobacterial and oxalobacteraceal 357 communities in an experimental agricultural field. Applied and Environmental Microbiology 358 79:5291-5301. DOI 10.1128/AEM.01361-13

359

360 Cruz RS, Yañez-Ocampo G, Wong-Villarreal A. 2014. Effect of nodulating bacteria on the seed 361 germination of Capsicum spp. African Journal of Microbiology Research 8:659-663. DOI 362 $\underline{10.5897 / A J M R 2013.6494}$

363

364

Dardanelli MS, Manyani H, González-Barroso S, Rodríguez-Carvajal MA, Gil-Serrano AM, 365 Espuny MR, López-Baena FJ, Bellogín RA, Megías M, Ollero FJ. 2009. Effect of the presence 366 of the plant growth promoting rhizobacterium (PGPR) Chryseobacterium balustinum Aur9 and 367 salt stress in the pattern of flavonoids exuded by soybean roots. Plant and Soil 328:483-493. DOI $\underline{10.1007 / \mathrm{s} 11104-009-0127-6}$

369

370 Datta C, Basu PS. 2000. Indole acetic acid production by a Rhizobium species from root nodules 371 of a leguminous shrub, Cajanus cajan. Microbiological Research 155:123-127. DOI

$372 \underline{10.1016 / \mathrm{s} 0944-5013(00) 80047-6}$ 
374 de los Santos MC, Taulé C, Mareque C, Beracochea M, Battistoni F. 2015. Identification and

375 characterization of the part of the bacterial community associated with field-grown tall fescue

376 (Festuca arundinacea) cv. SFRO Don Tomás in Uruguay. Annals of Microbiology 66:329-342.

377 DOI $\underline{10.1007 / \mathrm{s} 13213-015-1113-2}$

378

379 Diaz Herrera S, Grossi C, Zawoznik M, Groppa MD. 2016. Wheat seeds harbour bacterial 380 endophytes with potential as plant growth promoters and biocontrol agents of Fusarium 381 graminearum. Microbiological Research 186-187:37-43. DOI 10.1016/j.micres.2016.03.002

382

383 Faith DP. 1992. Conservation evaluation and phylogenetic diversity. Biological Conservation 384 61:1-10. DOI 10.1016/0006-3207(92)91201-3

385

386 Faramarzi M, Fazeli M, Yazdi MT, Adrangi S, Al-Ahmadi KJ, Tasharrofi N, Mohseni FA. 2009. 387 Optimization of cultural conditions for production of chitinase by a soil isolate of Massilia 388 timonae. Biotechnology 8:93-99. DOI 10.3923/biotech.2009.93.99

389

390 Feng Y, Shen D, Song W. 2006. Rice endophyte Pantoea agglomerans YS19 promotes host 391 plant growth and affects allocations of host photosynthates. Journal of Applied Microbiology 392 100:938-945. DOI 10.1111/j.1365-2672.2006.02843.x

393

394 Ferreira A, Quecine MC, Lacava PT, Oda S, Azevedo JL, Araujo WL. 2008. Diversity of 395 endophytic bacteria from Eucalyptus species seeds and colonization of seedlings by Pantoea 396 agglomerans. FEMS Microbiology Letters 287:8-14. DOI 10.1111/j.1574-6968.2008.01258.x 
398 Garbeva P, Silby MW, Raaijmakers JM, Levy SB, Boer W. 2011. Transcriptional and 399 antagonistic responses of Pseudomonas fluorescens Pf0-1 to phylogenetically different bacterial 400 competitors. ISME J 5:973-985. DOI 10.1038/ismej.2010.196

401

402 Gond SK, Bergen MS, Torres MS, White JF, Kharwar RN. 2015a. Effect of bacterial endophyte 403 on expression of defense genes in Indian popcorn against Fusarium moniliforme. Symbiosis 404 66:133-140. DOI 10.1007/s13199-015-0348-9

405

406 Gond SK, Torres MS, Bergen MS, Helsel Z, White JF, Jr. 2015b. Induction of salt tolerance and 407 up-regulation of aquaporin genes in tropical corn by rhizobacterium Pantoea agglomerans. 408 Letters in Applied Microbiology 60:392-399. DOI 10.1111/lam.12385

409

410 Griffiths RI, Whiteley AS, O'Donnell AG, Bailey MJ. 2003. Physiological and community

411 responses of established grassland bacterial populations to water stress. Applied and

412 Environmental Microbiology 69:6961-6968. DOI 10.1128/aem.69.12.6961-6968.2003

413

414 Gutiérrez Mañero FJ, Probanza A, Ramos B, Colón Flores JJ, Lucas García JA. 2003. Effects of 415 culture filtrates of rhizobacteria isolated from wild lupine on germination, growth, and biological 416 nitrogen fixation of lupine seedlings. Journal of Plant Nutrition 26:1101-1115. DOI

$417 \quad 10.1081 /$ PLN-120020078

418 
419 Gutierrez-Zamora M, Martınez-Romero E. 2001. Natural endophytic association between

420 Rhizobium etli and maize (Zea mays L.). Journal of Biotechnology 91:117-126. DOI

$421 \quad 10.1016 / \mathrm{S} 0168-1656(01) 00332-7$

422

423 Haack FS, Poehlein A, Kroger C, Voigt CA, Piepenbring M, Bode HB, Daniel R, Schafer W, 424 Streit WR. 2016. Molecular keys to the Janthinobacterium and Duganella spp. interaction with 425 the plant pathogen Fusarium graminearum. Frontiers in Microbiology 7:1668. DOI $426 \quad 10.3389 /$ fmicb. 2016.01668

427

428

Hardoim PR, van Overbeek LS, Berg G, Pirttila AM, Compant S, Campisano A, Doring M, 429 Sessitsch A. 2015. The hidden world within plants: ecological and evolutionary considerations 430 for defining functioning of microbial endophytes. Microbiology and Molecular Biology Reviews 431 79:293-320. DOI 10.1128/MMBR.00050-14

432

433 Henning JA, Weston DJ, Pelletier DA, Timm CM, Jawdy SS, Classen AT. 2016. Root bacterial 434 endophytes alter plant phenotype, but not physiology. PeerJ 4:e2606 DOI 10.7717/peerj.2606 435

436 Irizarry I, White JF. 2017. Application of bacteria from non-cultivated plants to promote growth, 437 alter root architecture and alleviate salt stress of cotton. Journal of Applied Microbiology 438 122:1110-1120. DOI $\underline{10.1111 / j a m .13414}$ 
440 Johnston-Monje D, Lundberg DS, Lazarovits G, Reis VM, Raizada MN. 2016. Bacterial

441 populations in juvenile maize rhizospheres originate from both seed and soil. Plant and Soil

442 405:337-355. DOI $\underline{\text { 10.1007/s11104-016-2826-0 }}$

443

444

445 Johnston-Monje D, Raizada MN. 2011. Conservation and diversity of seed associated

446 endophyes in Zea across boundaries of evolution, ethnography and ecology. PLoS

447 ONE 6:e20396. DOI 10.1371/journal.pone.0020396

448

449 Kiers ET, Rousseau RA, West SA, Denison RF. 2003. Host sanctions and the legume-rhizobium 450 mutualism. Nature 425:78-81. DOI 10.1038/nature01931

451

452 Klindworth A, Pruesse E, Schweer T, Peplies J, Quast C, Horn M, Glöckner FO. 2013

453 Evaluation of general 16S ribosomal RNA gene PCR primers for classical and next-generation

454 sequencing-based diversity studies. Nucleic Acids Research 41(1):e1-e1. DOI

455 doi.org/10.1093/nar/gks808

456

457 Kolton M, Erlacher A, Berg G, Cytryn E. 2016. The Flavobacterium genus in the plant

458 holobiont: ecological, physiological, and applicative insights. In: Castro-Sowinski S, ed.

459 Microbial Models: From Environmental to Industrial Sustainability: Springer, 189-207.

460 
461 Lee HR, Han SI, Rhee KH, Whang KS. 2013. Mucilaginibacter herbaticus sp. nov., isolated 462 from the rhizosphere of the medicinal plant Angelica sinensis. International Journal of 463 Systematic and Evolutionary Microbiology 63:2787-2793. DOI 10.1099/ijs.0.038398-0 464

465 Liu PP, Montgomery TA, Fahlgren N, Kasschau KD, Nonogaki H, Carrington JC. 2007.

466 Repression of AUXIN RESPONSE FACTOR10 by microRNA160 is critical for seed germination 467 and post-germination stages. The Plant Journal 52:133-146. DOI 10.1111/j.1365-

$468 \quad \underline{313 X .2007 .03218 . x}$

469

470 Madhaiyan M, Poonguzhali S, Lee JS, Senthilkumar M, Lee KC, Sundaram S. 2010.

471 Mucilaginibacter gossypii sp. nov. and Mucilaginibacter gossypiicola sp. nov., plant-growth-

472 promoting bacteria isolated from cotton rhizosphere soils. International Journal of Systematic 473 and Evolutionary Microbiology 60:2451-2457. DOI 10.1099/ijs.0.018713-0

474

475 Mannisto MK, Tiirola M, McConnell J, Haggblom MM. 2010. Mucilaginibacter frigoritolerans 476 sp. nov., Mucilaginibacter lappiensis sp. nov. and Mucilaginibacter mallensis sp. nov., isolated 477 from soil and lichen samples. International Journal of Systematic and Evolutionary 478 Microbiology 60:2849-2856. DOI 10.1099/ijs.0.019364-0

479

480 Mano H, Tanaka F, Watanabe A, Kaga H, Okunishi S, Morisaki H. 2006. Culturable surface and 481 endophytic bacterial flora of the maturing seeds of rice plants (Oryza sativa) cultivated in a 482 paddy field. Microbes and Environments 21:86-100. DOI 10.1264/jsme2.21.86 483 
484 Meyer WA, Torres MS, White JF. 2012. Biology and applications of fungal endophytes in 485 turfgrasses. In: Stier J, Horgan B, Bonos S, ed. Turfgrass: Biology, Use and Management. 486 Madison: American Society of Agronomy, 713-731.

487

488 Miransari M, Smith DL. 2014. Plant hormones and seed germination. Environmental and 489 Experimental Botany 99:110-121. DOI 10.1016/j.envexpbot.2013.11.005

490

491 Ofek M, Hadar Y, Minz D. 2012. Ecology of root colonizing Massilia (Oxalobacteraceae). PLoS 492 One 7:e40117. DOI 10.1371/journal.pone.0040117

493

494 Okunishi S, Sako K, Mano H, Imamura A, Morisaki H. 2005. Bacterial flora of endophytes in 495 the maturing seed of cultivated rice (Oryza sativa). Microbes and Environments 20:168-177.

496 DOI $\underline{10.1264 / \text { jsme2.20.168 }}$

497

498

Oteino N, Lally RD, Kiwanuka S, Lloyd A, Ryan D, Germaine KJ, Dowling DN. 2015. Plant 499 growth promotion induced by phosphate solubilizing endophytic Pseudomonas isolates.

500

Frontiers in Microbiology 6:745. DOI 10.3389/fmicb.2015.00745

501

502

Pace NR, Stahl DA, Lane DJ, Olsen GJ. 1986. The analysis of natural microbial populations by

503 ribosomal RNA sequences. In: Marshall KC, ed. Advances in Microbial Ecology. Berlin:

504 Springer, 1-55.

505 
506 Pedrini S, Merritt DJ, Stevens J, Dixon K. 2017. Seed coating: science or marketing spin? Trends

507 in Plant Science 22:106-116. DOI: $10.1016 / \mathrm{j} . t p l a n t s .2016 .11 .002$

508

509 Poinar HN, Schwarz C, Qi J, Shapiro B, MacPhee RDE, Buigues B, Tikhonov A, Huson DH,

510 Tomsho LP, Auch A. 2006. Metagenomics to paleogenomics: large-scale sequencing of

511 mammoth DNA. Science 311:392-394. DOI 10.1126/science.1123360

512

513 Price MN, Dehal PS, Arkin AP. 2010. FastTree 2 - Approximately maximum-likelihood trees

514 for large alignments. PLoS ONE 5:e9490. DOI 10.1371/journal.pone.0009490

515

516 Prieto P, and Mercado-Blanco J. 2008. Endophytic colonization of olive roots by the biocontrol

517 strain Pseudomonas fluorescens PICF7. FEMS Microbiology Ecology 64:297-306. DOI

$518 \quad \underline{10.1111 / \mathrm{j} .1574-6941.2008 .00450 . \mathrm{x}}$

519

520 Riesenfeld CS, Schloss PD, Handelsman J. 2004. Metagenomics: genomic analysis of microbial

521 communities. Annual Review of Genetics 38:525-552. DOI

522 10.1146/annurev.genet.38.072902.091216

523

524 Rognes T, Flouri T, Nichols B, Quince C, Mahé F. 2016. VSEARCH: a versatile open source

525 tool for metagenomics. PeerJ 4:e258 10.7717/peerj.2584

526 
527 Ruiz D, Agaras B, de Werra P, Wall LG, Valverde C. 2011. Characterization and screening of 528 plant probiotic traits of bacteria isolated from rice seeds cultivated in Argentina. Journal of 529 Microbiology 49:902-912. DOI 10.1007/s12275-011-1073-6

530

531 Rybakova D, Cernava T, Köberl M, Liebminger S, Etemadi M, Berg G. 2015. Endophytes532 assisted biocontrol: novel insights in ecology and the mode of action of Paenibacillus. Plant and 533 Soil 405:125-140. DOI 10.1007/s11104-015-2526-1

534

535 Schmidt TM, DeLong EF, Pace NR. 1991. Analysis of a marine picoplankton community by $16 \mathrm{~S}$ 536 rRNA gene cloning and sequencing. Journal of Bacteriology 173:4371-4378. DOI

$537 \quad \underline{10.1128 / \mathrm{jb} .173 .14 .4371-4378.1991}$

538

539 Shaik SP, Thomas P. 2019. In vitro activation of seed-transmitted cultivation-recalcitrant

540 endophytic bacteria in tomato and host-endophyte mutualism. Microorganisms 7:132. DOI

$541 \quad 10.3390 /$ microorganisms 7050132

542

543 Soltani A-A, Khavazi K, Asadi-Rahmani H, Omidvari M, Abaszadeh Dahaji P, Mirhoseyni H.

544 2010. Plant growth promoting characteristics in some Flavobacterium spp. isolated from soils of 545 Iran. Journal of Agricultural Science 2:106. DOI 10.5539/jas.v2n4p106

546

547 Somova L, Pechurkin N, Sarangova A, Pisman T. 2001. Effect of bacterial population density on 548 germination wheat seeds and dynamics of simple artificial ecosystems. Advances in Space

549 Research 27:1611-1615. DOI 10.1016/S0273-1177(01)00257-5 
550

551 Steven B, Lionard M, Kuske CR, Vincent WF. 2013. High bacterial diversity of biological soil

552 crusts in water tracks over permafrost in the high arctic polar desert. PLoS One 8:e71489. DOI

$553 \quad \underline{10.1371 / \text { journal.pone.0071489 }}$

554

555 Storch D, Bohdalková E, Okie J. 2018. The more-individuals hypothesis revisited: the role of 556 community abundance in species richness regulation and the productivity-diversity relationship.

557 Ecology Letters 21:920-937.

558

559 Suzuki S, He Y, Oyaizu H. 2003. Indole-3-acetic acid production in Pseudomonas fluorescens

560 HP72 and its association with suppression of creeping bentgrass brown patch. Current

561 Microbiology 47:138-143. DOI 10.1007/s00284-002-3968-2

562

563 Tsavkelova EA, Cherdyntseva TA, Botina SG, Netrusov AI. 2007. Bacteria associated with

564 orchid roots and microbial production of auxin. Microbiological Research 162:69-76. DOI

$565 \quad \underline{10.1016 / \text { j.micres.2006.07.014 }}$

566

567 Verma P. 2019. Seed endophytes in crop plants: metagenomic approaches to study the functional 568 roles and interactions. In: Verma SK, White, JF, ed. Seed Endophytes. Berlin: Springer, 483-507. 569

570 Verma S, Kingsley K, Irizarry I, Bergen M, Kharwar R, White JF. 2017. Seed vectored 571 endophytic bacteria modulate development of rice seedlings. Journal of Applied 572 Microbiology. 122: 1680-1691. DOI 10.1111/jam.13463 
573

574 Verma SK, Kingsley K, Bergen M, English C, Elmore M, Kharwar RN, White JF. 2018.

575 Bacterial endophytes from rice cut grass (Leersia oryzoides L.) increase growth, promote root 576 gravitropic response, stimulate root hair formation, and protect rice seedlings from 577 disease. Plant Soil 422: 223-238. DOI 10.1007/s11104-017-3339-1

578

579 White JF, Kingsley KL, Butterworth S, Brindisi L, Gatei JW, Elmore MT, Verma SK, Yao X, 580 Kowalski KP. 2019. Seed-vectored microbes: their roles in improving seedling fitness and 581 competitor plant suppression. In: Verma SK, White, JF, ed. Seed Endophytes. Berlin: Springer,358220.

583

584 White JF, Kingsley KL, Verma SK, Kowalski KP. 2018. Rhizophagy cycle: An oxidative 585 process in plants for nutrient extraction from symbiotic microbes. Microorganisms 6: 95. DOI $586 \quad 10.3390 /$ microorganisms6030095

587

588 White JF, Torres MS, Johnson H, Irizarry I, Tadych M. 2014. A functional view of plant 589 microbiomes: endosymbiotic systems that enhance plant growth and survival. In: Verma VC, 590 Gange AC, ed. Advances in Endophytic Research. Berlin: Springer, 425-439.

591

592 White Jr J. 1987. Widespread distribution of endophytes in the Poaceae. Plant Disease 71:340-

593 342. DOI 10.1094/PD-71-0340

594 
595 Yanni YG, Rizk R, Corich V, Squartini A, Ninke K, Philip-Hollingsworth S, Orgambide G, De

596 Bruijn F, Stoltzfus J, Buckley D. 1997. Natural endophytic association between Rhizobium

597 leguminosarum bv. trifolii and rice roots and assessment of its potential to promote rice growth.

598 Plant and Soil 194:99-114. DOI 10.1023/A:1004269902246

599

600 Yuan CL, Mou CX, Wu WL, Guo YB. 2010. Effect of different fertilization treatments on

601 indole-3-acetic acid producing bacteria in soil. Journal of Soils and Sediments 11:322-329. DOI

$602 \underline{10.1007 / \mathrm{s} 11368-010-0315-2}$

603

604 Zeglin LH, Dahm CN, Barrett JE, Gooseff MN, Fitpatrick SK, Takacs-Vesbach CD. 2011.

605 Bacterial community structure along moisture gradients in the parafluvial sediments of two

606 ephemeral desert streams. Microbial Ecology 61:543-556. DOI 10.1007/s00248-010-9782-7

607

608 Zhu YL, She XP, Wang JS, Lv HY. 2017. Endophytic bacterial effects on seed germination and 609 mobilization of reserves in Ammodendron biofolium. Pakistan Journal of Botany 49:2029-2035. 
Figure 1

Graphical workflow of metagenomic analysis in our study. 
Query

Sequences

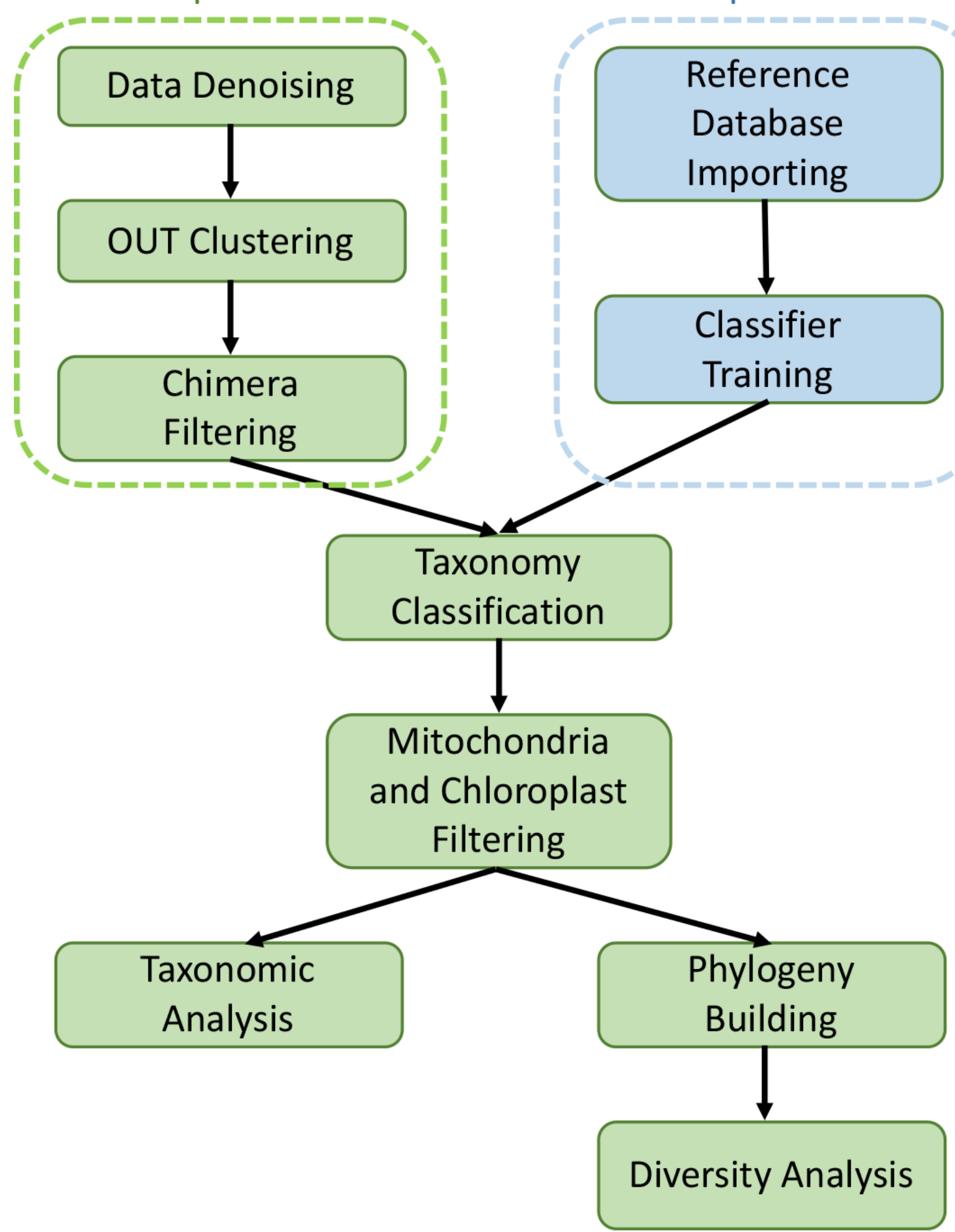

Reference

Sequences

Reference

Classifier

Training 
Figure 2

Bar plot analysis illustrating the relative abundance and distribution of the OTUs assigned to class-level taxonomy.

LM: low moisture; HM: high moisture. 

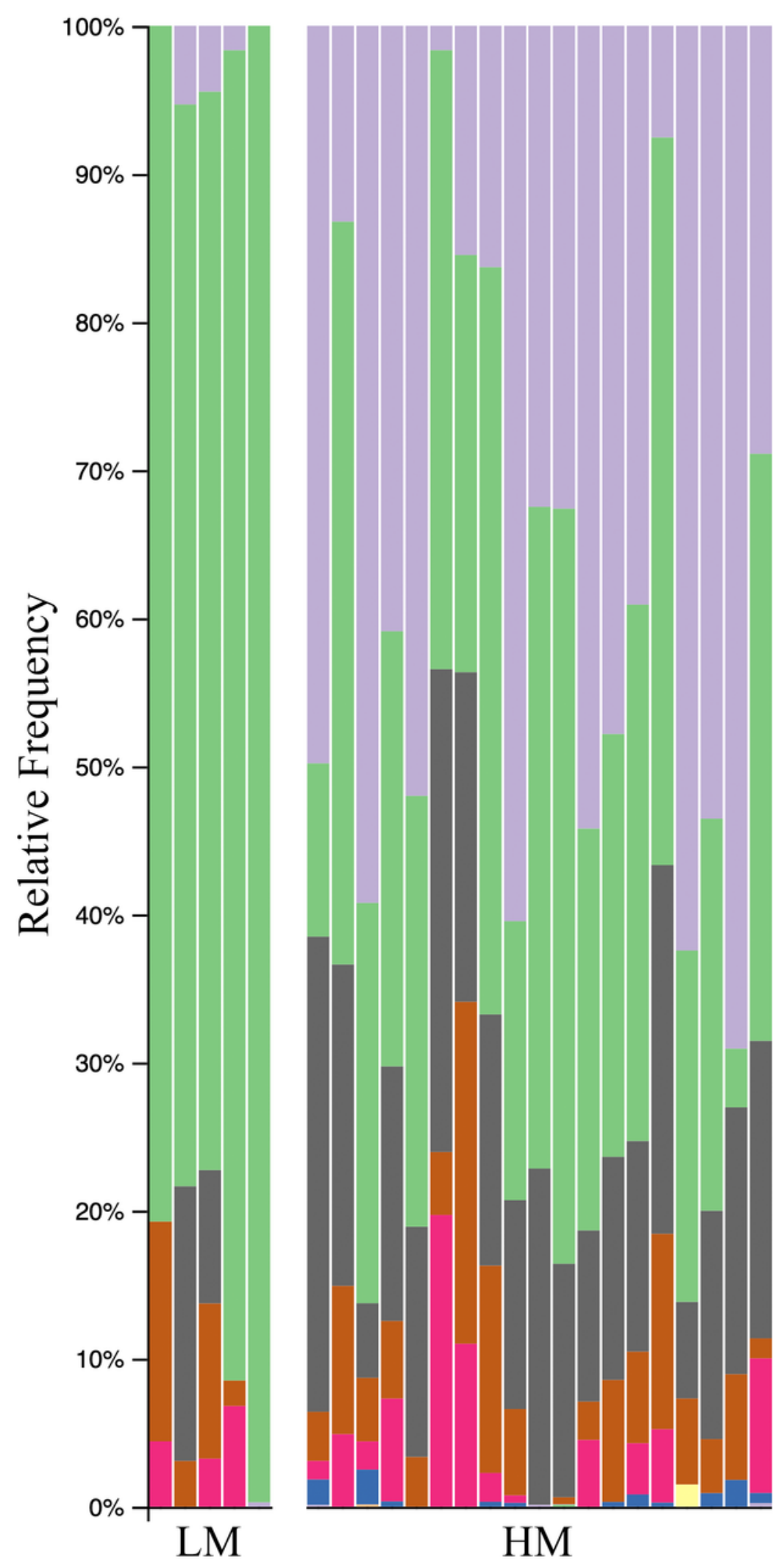

\section{Bacteroidia}

Gammaproteobacteria Alphaproteobacteria Actinobacteria Bacilli Saccharimonadia Thermoleophilia Acidimicrobiia Unknown Unassigned 
Figure 3

Box plots depicting the Faith's Phylogenetic Diversity for different climate conditions $(A)$, different genera (B), and different species (C).
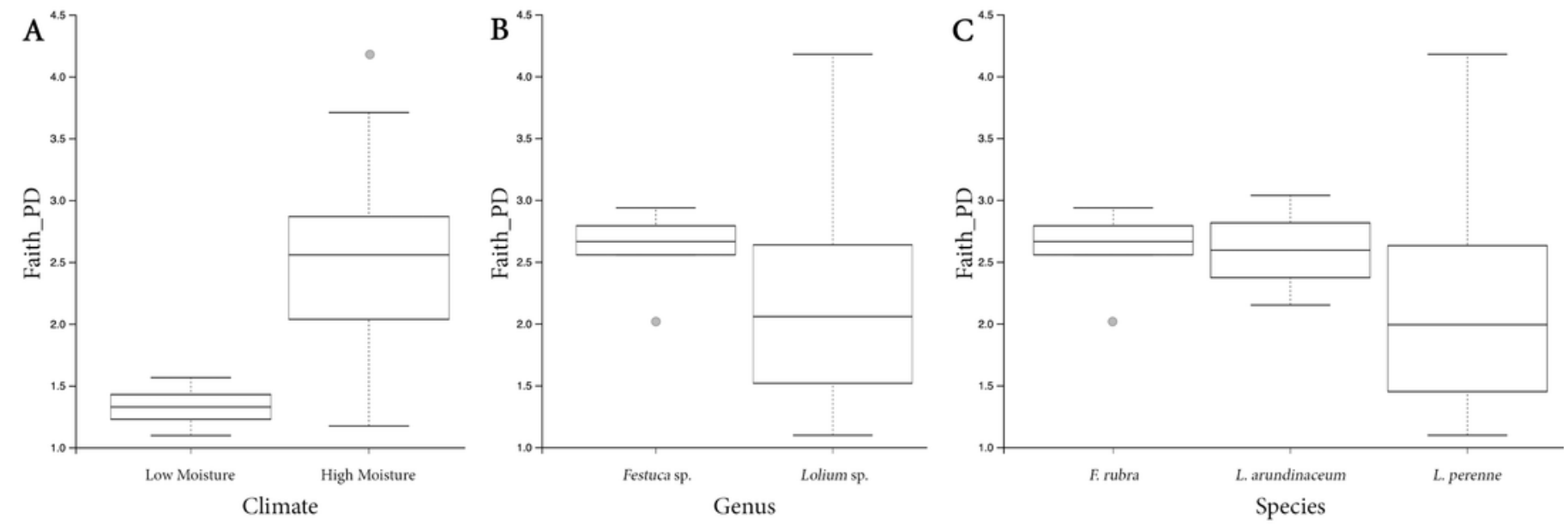
Figure 4

PCoA Emperor plots based on Bray-Cuitis diversity matrix.

Samples are scattered concerning their bacterial community. Climates are represented by different colors: red - low moisture; blue - high moisture. Species were represented by different shapes: ring - Loium arudinacea; sphere - Lolium perenne; square - Festuca rubra. 
?
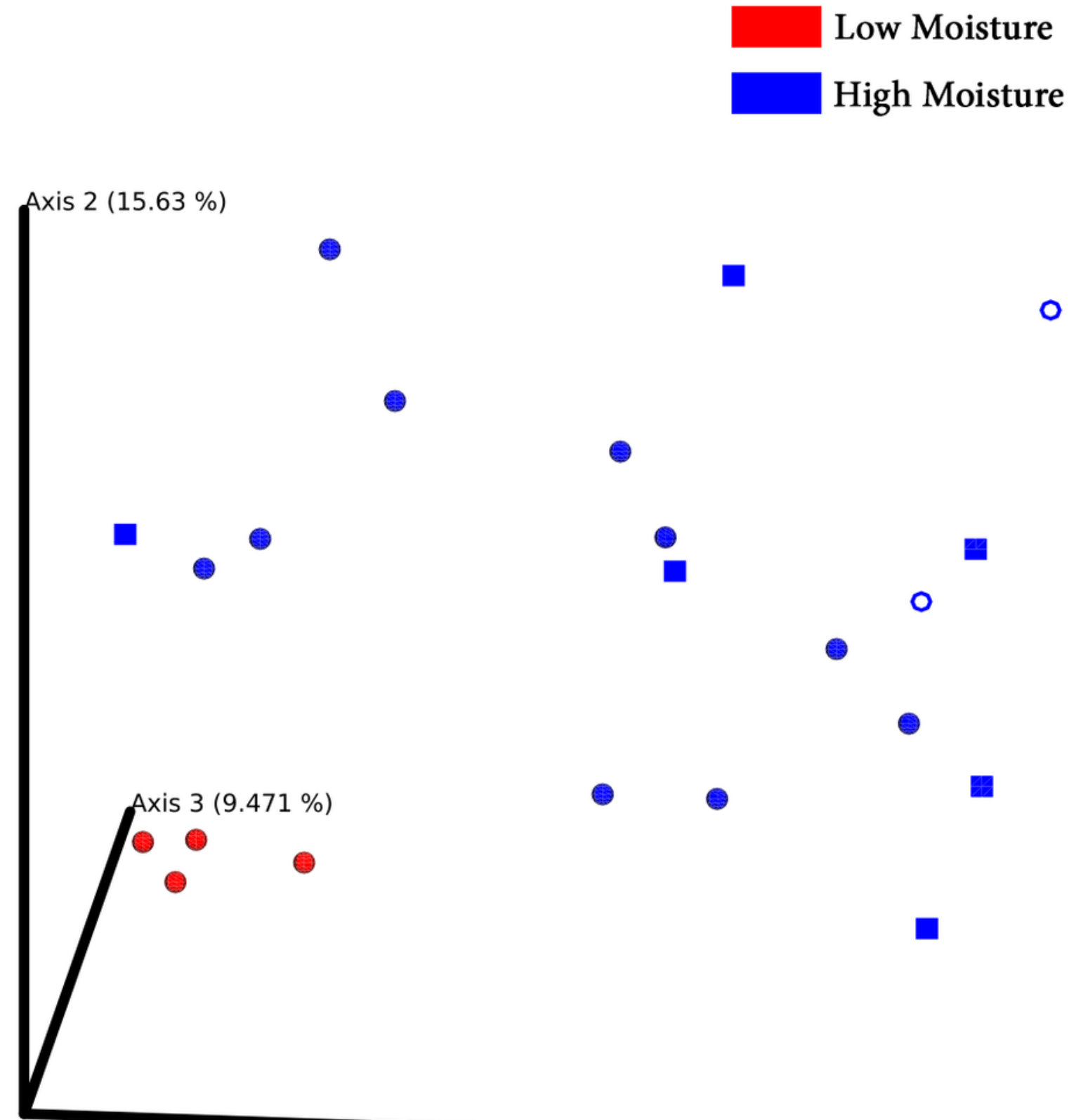

Axis 1 (25.82 \%) 


\section{Figure 5}

Venn diagrams showing the number of shared bacterial genera between different climate (A) and among different turf species (B).

LM: low moisture; HM: high moisture; Fr: Festuca rubra; Lp: Lolium perenne; La: Loium arudinacea.

A

B
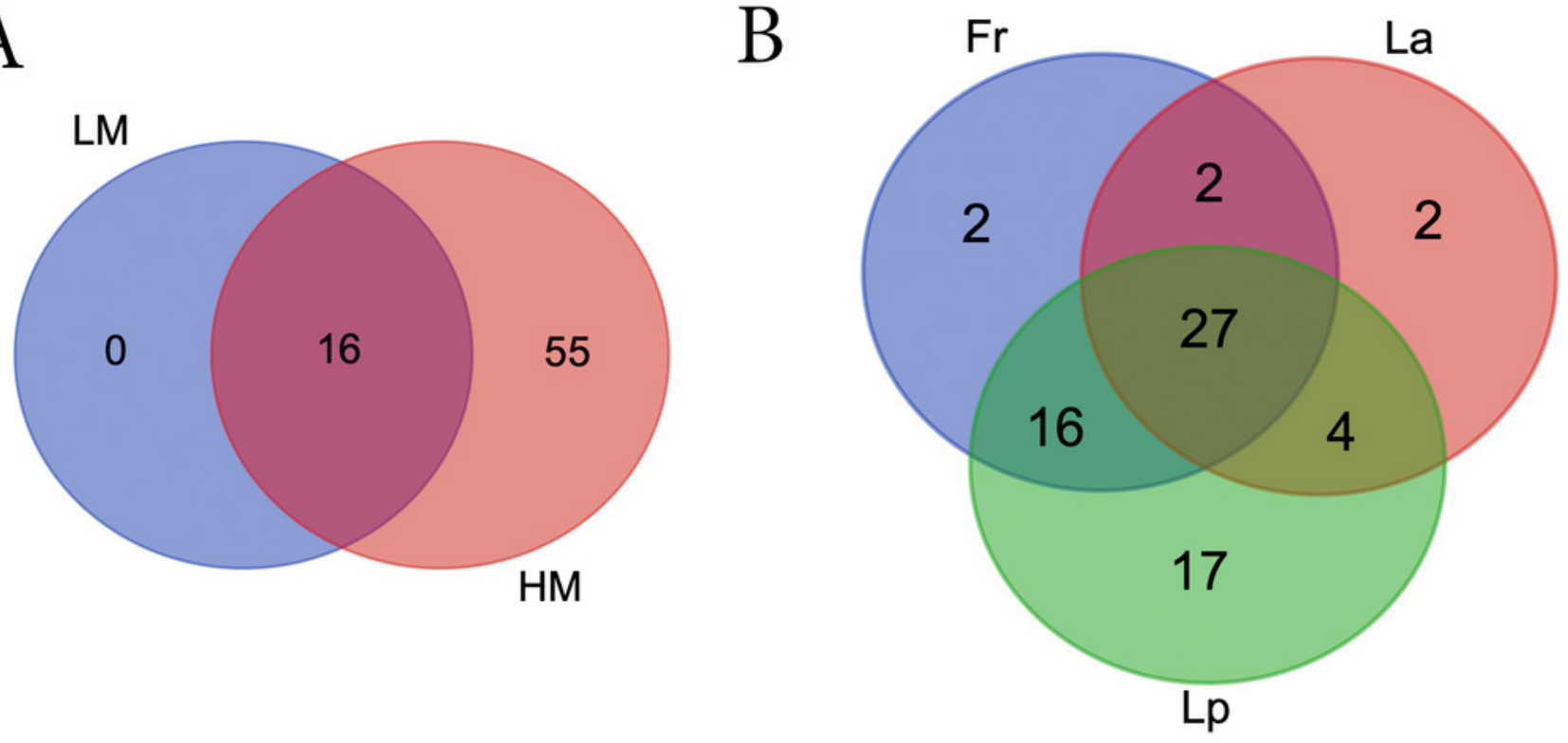
Figure 6

Correlation of seed germination rate with abundance of bacteria groups at different taxonomy levels.

Phylum level: A and B; Class level: C; Order level: D and E; Family level: F - H; Genus level: I K; Species level: L.

A



$\mathrm{D}$



G

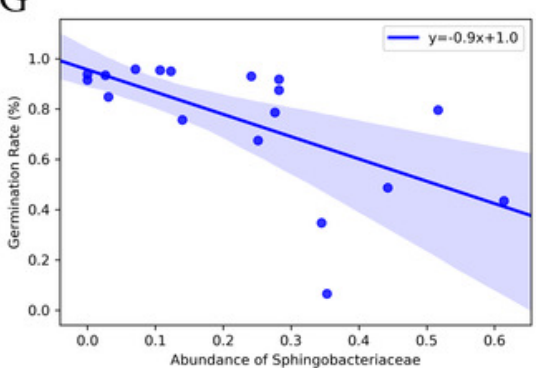

J

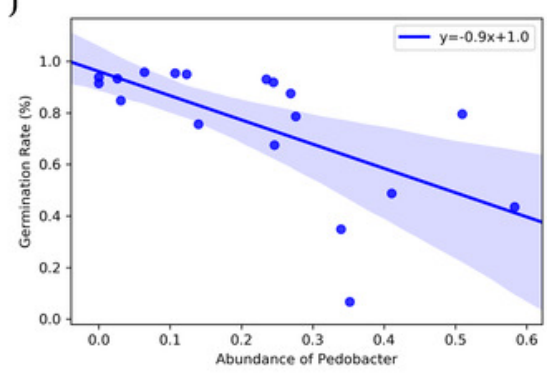

$\mathrm{B}$



E

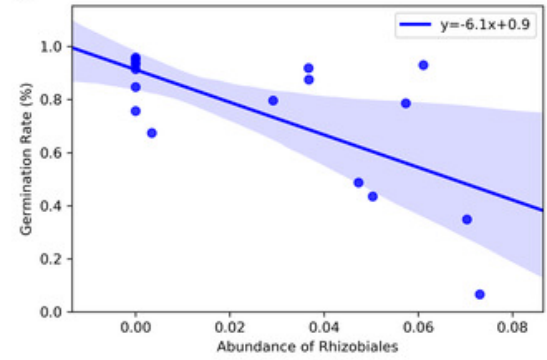

$\mathrm{H}$

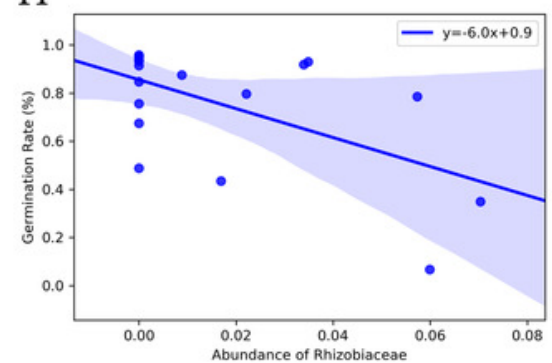

K



C

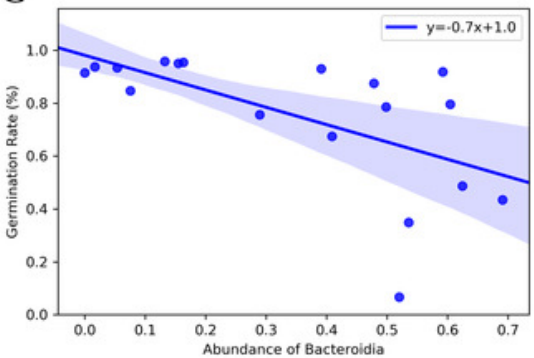

F

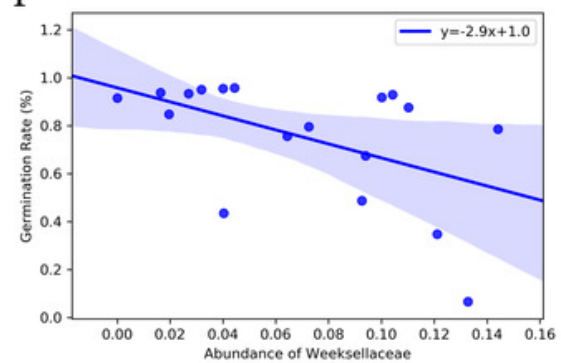

I

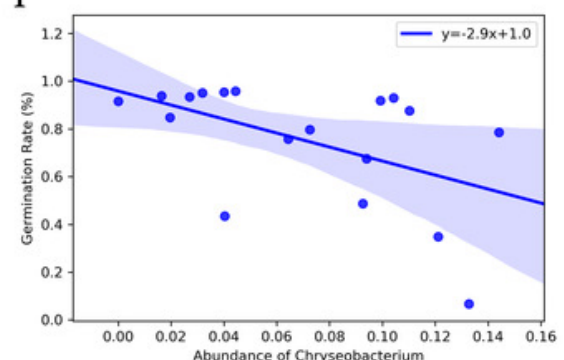

L

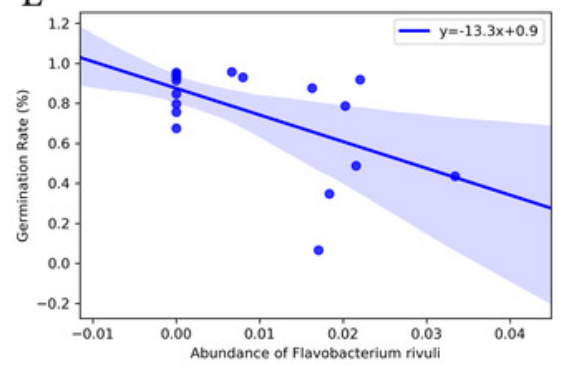




\section{Figure 7}

Correlation of average seed germination time with abundance of bacteria groups at different taxonomy levels.

Phylum level: A - C; Class level: D - F; Order level: G - K; Family level: L - P; Genus level: Q T; Species level: U. 

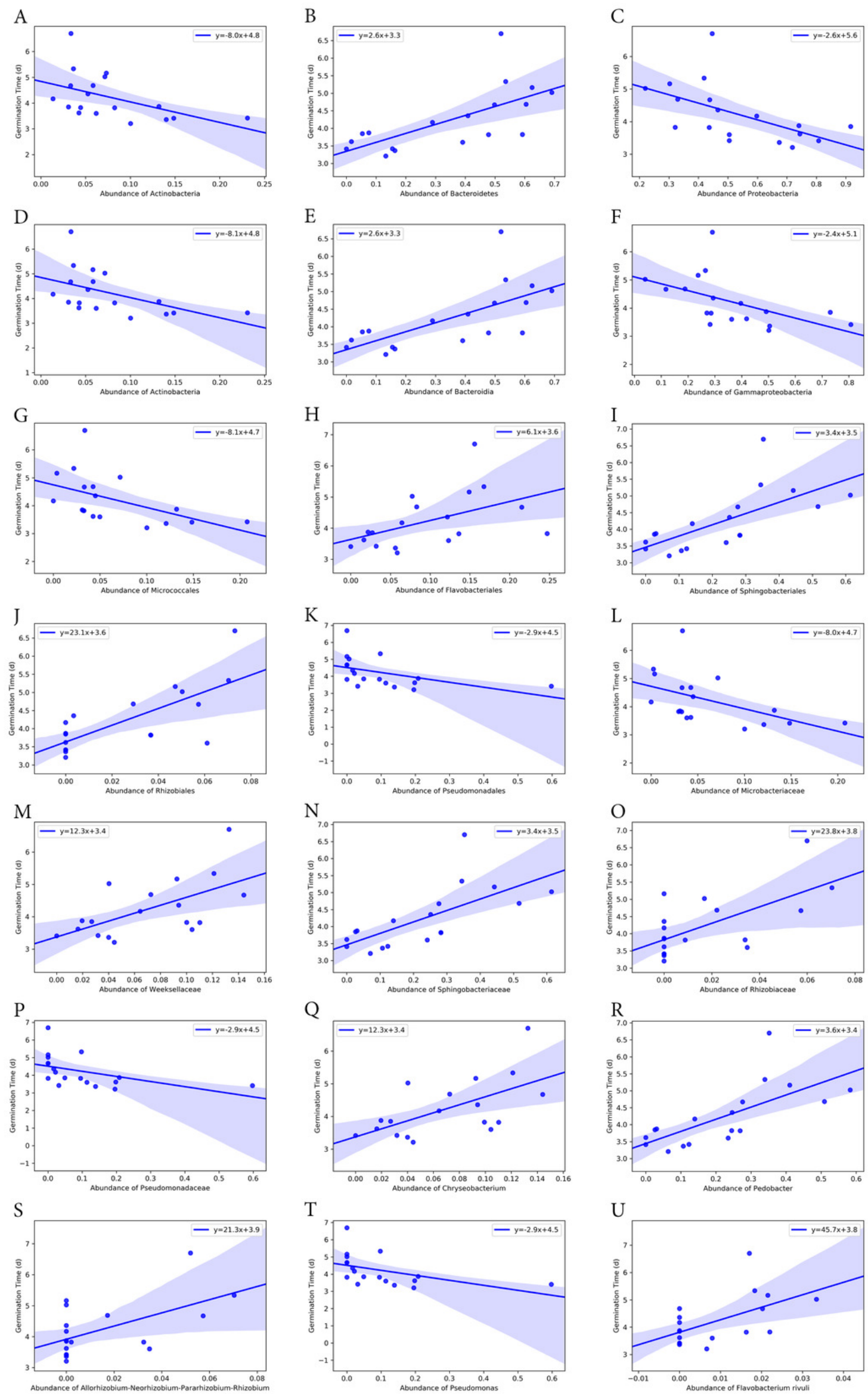

Peer) reviewing PDF | (2019:08:40181:3:0:NEW 9 Dec 2019) 


\section{Table 1 (on next page)}

Composition of bacterial community from LM and HM climate seeds.

*: Rhizobium group also includes Allorhizobium, Neorhizobium, and Pararhizobium.

**: Bacterial groups without significant difference between LM and HM.

†: Bacterial groups with significant difference between LM and HM. 
1

\begin{tabular}{|c|c|c|c|c|}
\hline \multirow{2}{*}{ Taxa level } & \multirow{2}{*}{ Taxa name } & \multicolumn{3}{|c|}{ Ave. Percentage } \\
\hline & & LM & HM & Combined \\
\hline \multirow[t]{5}{*}{ Phylum } & Actinobacteria ** & $6 \%$ & $7 \%$ & $6 \%$ \\
\hline & Bacteroidetes $\dagger$ & $2 \%$ & $39 \%$ & $40 \%$ \\
\hline & Firmicutes $* *$ & $3 \%$ & $4 \%$ & $3 \%$ \\
\hline & Patescibacteria & - & $<1 \%$ & $<1 \%$ \\
\hline & Proteobacteria $\dagger$ & $89 \%$ & $50 \%$ & $51 \%$ \\
\hline \multirow[t]{6}{*}{ Class } & Actinobacteria $* *$ & $6 \%$ & $6 \%$ & $6 \%$ \\
\hline & Bacteroidia & $2 \%$ & $39 \%$ & $40 \%$ \\
\hline & Bacilli ** & $3 \%$ & $4 \%$ & $3 \%$ \\
\hline & Saccharimonadia & - & $<1 \%$ & $<1 \%$ \\
\hline & Alphaproteobacteria $\dagger$ & $6 \%$ & $18 \%$ & $15 \%$ \\
\hline & Gammaproteobacteria $\dagger$ & $83 \%$ & $32 \%$ & $36 \%$ \\
\hline \multirow[t]{11}{*}{ Order } & Micrococcales ** & $6 \%$ & $5 \%$ & $5 \%$ \\
\hline & Cytophagales & $<1 \%$ & $2 \%$ & $2 \%$ \\
\hline & Flavobacteriales $\dagger$ & $<1 \%$ & $11 \%$ & $9 \%$ \\
\hline & Sphingobacteriales $\dagger$ & $1 \%$ & $26 \%$ & $21 \%$ \\
\hline & Bacillales $* *$ & $3 \%$ & $4 \%$ & $4 \%$ \\
\hline & Saccharimonadales & - & $<1 \%$ & $<1 \%$ \\
\hline & Rhizobiales & - & $3 \%$ & $2 \%$ \\
\hline & Sphingomonadales $\dagger$ & $6 \%$ & $15 \%$ & $13 \%$ \\
\hline & Betaproteobacteriales $\uparrow$ & $30 \%$ & $13 \%$ & $17 \%$ \\
\hline & Enterobacteriales $\dagger$ & $24 \%$ & $12 \%$ & $15 \%$ \\
\hline & Pseudomonadales $\dagger$ & $29 \%$ & $6 \%$ & $11 \%$ \\
\hline \multirow[t]{11}{*}{ Family } & Microbacteriaceae ** & $6 \%$ & $5 \%$ & $5 \%$ \\
\hline & Hymenobacteraceae & $<1 \%$ & $1 \%$ & $1 \%$ \\
\hline & Flavobacteriaceae $\dagger$ & $<1 \%$ & $3 \%$ & $3 \%$ \\
\hline & Weeksellaceae $\dagger$ & $<1 \%$ & $7 \%$ & $6 \%$ \\
\hline & Sphingobacteriaceae $\dagger$ & $1 \%$ & $26 \%$ & $21 \%$ \\
\hline & Paenibacillaceae ** & $3 \%$ & $4 \%$ & $4 \%$ \\
\hline & Rhizobiaceae $\dagger$ & - & $2 \%$ & $1 \%$ \\
\hline & Sphingomonadaceae $\dagger$ & $6 \%$ & $15 \%$ & $13 \%$ \\
\hline & Burkholderiaceae $\dagger$ & $30 \%$ & $13 \%$ & $17 \%$ \\
\hline & Enterobacteriaceae $\dagger$ & $24 \%$ & $12 \%$ & $15 \%$ \\
\hline & Pseudomonadaceae $\dagger$ & $29 \%$ & $6 \%$ & $11 \%$ \\
\hline \multirow[t]{7}{*}{ Genus } & Curtobacterium ** & $2 \%$ & $2 \%$ & $2 \%$ \\
\hline & Hymenobacter & $<1 \%$ & $1 \%$ & $1 \%$ \\
\hline & Flavobacterium $\dagger$ & $<1 \%$ & $3 \%$ & $3 \%$ \\
\hline & Chryseobacterium $\dagger$ & $<1 \%$ & $7 \%$ & $6 \%$ \\
\hline & Mucilaginibacter & - & $<1 \%$ & $<1 \%$ \\
\hline & Pedobacter $\dagger$ & $1 \%$ & $25 \%$ & $20 \%$ \\
\hline & Paenibacillus $* *$ & $3 \%$ & $4 \%$ & $4 \%$ \\
\hline
\end{tabular}






2 


\section{Table 2 (on next page)}

Seed-vectored bacterial genera shared Loium arudinacea, Lolium perenne, and Festuca rubra.

*: Rhizobium group also includes Allorhizobium, Neorhizobium, and Pararhizobium. 
1

\begin{tabular}{|c|c|}
\hline Phylum & Genus \\
\hline \multirow[t]{2}{*}{ Actinobacteria } & Curtobacterium \\
\hline & Sanguibacter \\
\hline \multirow[t]{9}{*}{ Bacteroidetes } & Chryseobacterium \\
\hline & Dyadobacter \\
\hline & Flavobacterium \\
\hline & Mucilaginibacter \\
\hline & Pedobacter \\
\hline & Sphingobacterium \\
\hline & Spirosoma \\
\hline & uncultured Sphingobacteriaceae \\
\hline & unknown Sphingobacteriaceae \\
\hline \multirow[t]{3}{*}{ Patescibacteria } & uncultured bacterium \\
\hline & uncultured Sphingobium sp. \\
\hline & unknown Saccharimonadales \\
\hline \multirow[t]{13}{*}{ Proteobacteria } & Rhizobium* $^{*}$ \\
\hline & Aureimonas \\
\hline & Brevundimonas \\
\hline & Devosia \\
\hline & Duganella \\
\hline & Erwinia \\
\hline & Massilia \\
\hline & Novosphingobium \\
\hline & Pantoea \\
\hline & Pigmentiphaga \\
\hline & Pseudomonas \\
\hline & Sphingomonas \\
\hline & Verticia \\
\hline
\end{tabular}

2 